\title{
Direct Current Measurements in Cochlear Implants: An in vivo and in vitro Study
}

\author{
Christie Q. Huang*, Paul M. Carter**, Robert K. Shepherd*, \\ Peter M. Seligman**, Bruce Tabor** and Graeme M. Clark* \\ *CRC Cochlear Implant, Speech \& Hearing Research, \\ University of Melbourne, Parkville 3052, Victoria, Australia \\ **Cochlear Limited, Lane Cove, 2066, NSW, Australia
}

\begin{abstract}
Direct current (DC) was measured both in vivo and in vitro in cochlear implant electrodes with stimulation at moderate to high pulse rates in monopolar and bipolar modes. In vivo $D C$ was approximately 2-3 times higher than that measured in vitro. In vivo $D C$ levels were $<100 \mathrm{nA}$ even at very high rates, although $D C$ levels increased as a function of stimulus rate and charge intensity. $D C$ levels were lower in the monopolar than in the bipolar stimulation condition. Stimulation with a monopolar capacitively coupled extracochlear electrode showed even lower $D C$ levels in the intracochlear electrodes. Our results indicated that the Nucleus electrode shorting system is able to maintain a low level of $D C$ during very high rate stimulation for both monopolar and bipolar modes.
\end{abstract}

\section{INTRODUCTION}

Electrical stimulation of neural tissue involves the transfer of charge to tissue via electrodes. The conversion from electron to ionic current takes place at the electrode-tissue interface by electrochemical processes. With a charge-balanced biphasic current pulse, there is always a small amount of charge remaining on the electrodes immediately following the second phase as a result of the slow kinetics of the oxidative-reductive reactions that store charge on the electrode [1]. There are two methods of charge recovery typically used in neural prostheses: i) capacitive coupling; ii) electrode shorting [2]. Capacitive coupling between the stimulator and electrodes prevents any long-term residual charge. However, capacitors occupy a significant volume of the implant package in a neural prosthesis with a large number of electrodes. The Nucleus multichannel cochlear implant shorts all electrodes between current pulses. Any remaining charge flows through a low resistance path that brings all electrodes to the same electrode potential and effectively minimizes direct current (DC) [2].

While there is no clearly defined maximum safe limit for DC, chronic stimulation studies have consistently shown DC levels of less than $100 \mathrm{nA}$ do not result in damage to the auditory nerve or the cochlear in general $[3,4,5,6,7]$. However, there is good evidence to suggest that DC levels in excess of 1-2 $\mu \mathrm{A}$ can result in significant neural damage [8].

While electrode shorting has been shown to be a safe and efficacious technique for minimizing $D C$ at low stimulus rates (and therefore relatively long shorting periods), at higher rates ( $>500$ pulses per second; pps) there is evidence of increased DC levels, particularly associated with high stimulus intensities $[9,10]$.

The purpose of the present study was to examine DC levels in vivo using high stimulus rates at stimulus intensities both within and outside normal clinical levels with monopolar and bipolar stimulation.

\section{MATERIALS AND METHODS}

Six healthy guinea pigs were anaesthetised with ketamine $(40 \mathrm{mg} / \mathrm{kg})$ and xylazine $(4 \mathrm{mg} / \mathrm{kg})$ and were maintained at surgical levels of anaesthesia during the experiment. The four most apical platinum (Pt) electrodes of a standard Nucleus electrode array were carefully inserted into the scala tympani. An extracochlear $\mathrm{Pt}$ electrode was placed in the musculature outside the cochlea.

Biphasic constant current pulses were generated from a modified, box-mounted version of the Nucleus CI24M receiver/stimulator. The Nucleus CI24M device was powered and controlled from a purpose built interface board connected in to an IBM PC. This system allowed an arbitrary sequence of stimulation pulses to be defined and repeatedly presented to the electrodes with parameters such as pulse width, current amplitude and stimulus rate all independently variable. Current pulses at total rates of $1,200-$ $14,500 \mathrm{pps}$ were delivered to the four electrodes. The current amplitude was set at $0.2,0.875$ or $1.75 \mathrm{~mA}$ and pulse widths of $26,50,100$ or $200 \mu$ s/phase were used in monopolar and bipolar stimulation modes. Each stimulus condition in the monopolar mode was performed with and without a capacitor in series with the extracochlear electrode.

A parallel combination of a $47 \mu \mathrm{F}$ capacitor and a $10 \mathrm{k} \Omega$ resistor was placed in series with each intracochlear electrode. The voltage across each RC circuit was measured using battery operated digital voltmeters (10 M $\Omega$ input impedance; Fluke $8060 \mathrm{~A}$ ) providing a resolution of 1 nanoampere ( $\mathrm{nA}$ ).

The care and use of animals involved in this study was approved by the Animal Experimentation Ethics Committee of the Royal Victorian Eye and Ear Hospital ('Cochlear Implants: Neural damage mechanisms in the auditory nerve' \# 92-016A).

\section{RESULTS:}

In a preliminary study using high intensity bipolar stimulation the DC level measured in vivo was 3.2 
and 2.8 times that of the values measured in human serum albumen and saline respectively. Because of the large discrepancy noted between the in vivo and in vitro values the decision was made to use an in vivo rather than an in vitro model for this study.

Both monopolar and bipolar stimulation showed DC levels increased as a function of stimulus rate, pulse width and stimulus intensity. In general, DC levels were higher in bipolar stimulation than in monopolar stimulation. Monopolar stimulation with a capacitively coupled extracochlear electrode showed even lower DC levels in the intracochlear electrodes.

For monopolar stimulation, using a capacitor in series with the extracochlear electrode, the DC levels were almost zero at pulse widths of 25 and 50 $\mu \mathrm{s} / \mathrm{phase}$ even at the highest rate $(8500-14,500 \mathrm{pps} / 4$ channels). With pulse widths of up to $200 \mu \mathrm{s} /$ phase or stimulus intensities up to $1.75 \mathrm{~mA}$, which are outside the normal clinical level, some DC levels (less than $30 \mathrm{nA}$ ) were observed. It should be noted that even in the case of a capacitively coupled extracochlear electrode it is still possible for small DC to be present in the intracochlear electrodes. This is because it is only necessary for the sum of DC in the intracochlear electrodes to be zero, not the individual electrode current. Stimulation without a coupling capacitor showed slightly higher DC level but still less than 100 $\mathrm{nA}$ for the same stimulus conditions.

Using a stimulus intensity of $0.875 \mathrm{~mA}$, the mean DC levels for bipolar stimulation (16 stimulating electrodes from 4 animals) were $80 \mathrm{nA}$ for 26 $\mu \mathrm{s} / \mathrm{phase}$; $105 \mathrm{nA}$ for $50 \mu \mathrm{s} / \mathrm{phase}$; and 138nA for 100 $\mu \mathrm{s} / \mathrm{phase}$ at the stimulus rates of 14500,8500 , and $4600 \mathrm{pps} / 4$ channels respectively, corresponding to a shorting period as low as $7 \mu \mathrm{s}$.

\section{DISCUSSION:}

There has been increasing interest in speech processing strategies using high pulse rate stimulation (>500-1000 pulses/s per channel) to provide fine temporal cues for cochlear implant patients. The present study has demonstrated that the Nucleus electrode shorting system can effectively minimize $D C$ at stimulus rates of up to $14500 \mathrm{pps} / 4$ channels with pulse widths of $26-50 \mu s /$ phase for both monopolar and bipolar stimulation. Monopolar stimulation showed even greater reduction in DC level in the intracochlear electrode, especially with a capacitively coupled ex tracochlear electrode, with DC levels of less than $30 \mathrm{nA}$ using stimulus intensities outside the normal clinical range. The results of this study showed DC increased as a function of stimulus rate, pulse width and stimulus intensity for both monopolar and bipolar stimulation. Our results were obtained from an animal model using a modified clinical device, indicating the data is clinically relevant. It has important practical implications for selection of safe stimulus parameters and stimulation , configurations for cochlear implants. The 'mechanism(s) responsible for the significantly elevated DC observed in vivo compared with in vitro are currently under investigation.

\section{REFERENCES:}

[1] P.M Carter, R.K Shepherd and J.F. Patrick, "Safety studies for a prototype nucleus 22 channel implant at high stimulation rates," Proc. IIIrd International congress on cochlear implant, Paris, April 1995, pp.159.

[2] J.F Patrick., P.M Seligman, D.K Money, J.A Kuzma, "Cochlear Prostheses", ChurchillLivingstone, Edinburgh, pp. 99-124, 1990.

[3] R.K Shepherd, G.M Clark, R.C Black, "Chronic electrical stimulation of the auditory nerve in cats: Physiological and histopathological results," Acta Otolaryngol (Stockh), Suppl. vol. 399, pp. 19-31, 1983.

[4] R.K Shepherd, "The cochlear prosthesis: Safety investigations," $\mathrm{PhD}$ Thesis, University of Melbourne, 1986.

[5] R.K Shepherd and G.M Clark, "Effect of high" electrical stimulus intensities on the auditory nerve using brain stem response audiometry," Ann. Otol. Rhinol. Laryngol. Supl. vol. 128, (96), pp. 50-53, 1987.

[6] J. Xu, R.K Shepherd, R.E Millard and G.M Clark, "Chronic electrical stimulation of the auditory nerve at high stimulus rates: a physiological and histopathlogical study," Hear. Res. vol. 105, pp. 1-29, 1997.

[7] D.F Ni, R.K Shepherd, H.L Seldon, S.A Xu, G.M Clark and R.E Millard, "Cochlear pathology, following chronic electrical stimulation of the auditory nerve. I: Normal hearing kittens," Hear. Res. vol. 62 , pp. 63-81, 1992.

[8] R.K Shepherd, J. Matsushima, R.E Millard and G.M. Clark, "Cochlear pathology following chronit electrical stimulation using non charge balanced stimuli," Acta Otolaryngol. (Stockh) vol. 111, pp. 848-860, 1991.

[9] M. Tykocinski., R.K Shepherd and G.M Clatk, "Reduction in excitability of the auditory nerve' following electrical stimulation at high stimulus rates," Hear. Res. vol. 88, pp. 124-142, 1995.

[10] C.Q Huang, R.K Shepherd, P.M Seligman and, G.M. Clark, "Acute effect of high rate stimulation os: the excitability of the auditory nerve," in 1991 Conference on Implantable Auditory prostheses. Asilomar, August 1997, pp.104. 


\section{University Library}

\section{- M M N E R VA A gateway to Melbourne's research publications}

Minerva Access is the Institutional Repository of The University of Melbourne

\section{Author/s:}

Huang, Christie Q.;Carter, Paul M.;Shepherd, Robert K.;Seligman, Peter M.;Tabor, Bruce;Clark, Graeme M.

Title:

Direct current measurements in cochlear implants: an in vivo and in vitro study

Date:

1998

\section{Citation:}

Huang, C. Q., Carter, P. M., Shepherd, R. K., Seligman, P. M., Tabor, B., \& Clark, G. M. (1998). Direct current measurements in cochlear implants: an in vivo and in vitro study. In Proceedings of 2nd International Conference on Bioelectromagnetism, Melbourne.

Persistent Link:

http://hdl.handle.net/11343/27018 